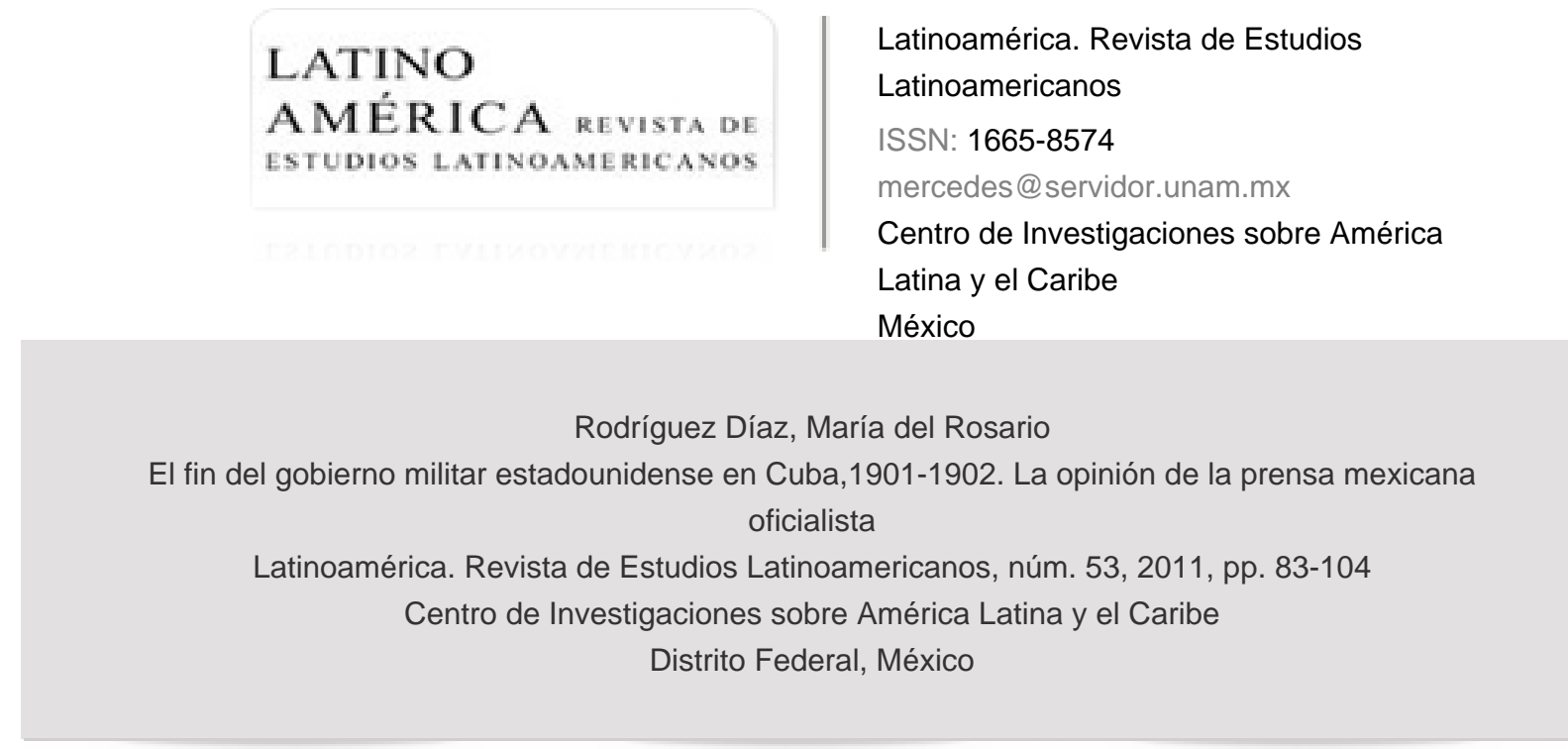

Disponible en: http://www.redalyc.org/articulo.oa?id=64021405005

Cómo citar el artículo

- Número completo

- Más información del artículo

- Página de la revista en redalyc.org

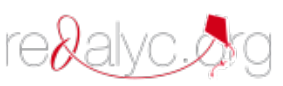

Sistema de Información Científica

Red de Revistas Científicas de América Latina, el Caribe, España y Portugal Proyecto académico sin fines de lucro, desarrollado bajo la iniciativa de acceso abierto 


\title{
El fin del gobierno militar estadounidense en Cuba, 1901-1902. La opinión de la prensa mexicana oficialista
}

María del Rosario Rodríguez Díaz*

\begin{abstract}
RESUMEN: Se analizan y reconstruyen las representaciones y opiniones del periódico oficialista El Imparcial ante el fin del gobierno militar estadounidense en Cuba y la candidatura de Tomás Estrada Palma, primer presidente de la República. Otro de los ejes de este trabajo es demostrar que las elecciones presidenciales de 1901-1902 fueron un elemento importante en la formación y generación de actitudes alrededor del actuar de Washington en el entorno geopolítico inmediato del México porfirista.

Palabras clave: Cuba-Estados Unidos, México-Prensa porfirista.

ABSTRACT: The Main objective of this proposal is to analyze and reconstruct the depictions and views of the Mexican Government newspaper El Imparcial before the end of the United States military Government in Cuba and the candidacy of Tomás Estrada Palma, first President of the Republic. Another axis of this work is to demonstrate that the presidential elections of 1901-1902 were an important element in the formation and generation of attitudes around act in Washington in the immediate geopolitical environment of the Mexico Diaz.

Key words: Cuba-Estados Unidos, Mexico-Porfirian Press.
\end{abstract}

"Universidad Michoacana de San Nicolás de Hidalgo (rdiaz@umich.mx). 
María del Rosario Rodriguez Díaz

\section{INTRODUCCIÓN}

$\mathrm{U}$

na vez concluida la fase militar del conflicto hispano-cubano-estadounidense de 1898, los asuntos cubanos dejaron de ocupar las primeras planas y las páginas centrales en la prensa mexicana. Sin embargo, las noticias del acontecer político de la Isla siguieron fluyendo de manera cotidiana en órganos periodísticos como El Imparcial, primer diario moderno de México - a decir de algunos estudiosos de la prensadebido a la maquinaria y tecnología empleada, así como al gran tiraje alcanzado; otro rasgo distintivo de este periódico era su carácter de órgano de propagación de las ideas y opiniones de la administración porfirista. Desde estas premisas seleccionamos este órgano, que nos permitirá reconstruir y analizar las representaciones y opiniones del mencionado periódico oficialista ante la candidatura de Tomás Estrada Palma, con el objetivo de demostrar que las elecciones presidenciales de 1901-1902 fueron un elemento importante en la formación y generación de actitudes en torno al actuar de Washington en el entorno geopolítico inmediato del México porfiriano.

\section{ESTADOS UNIDOS Y CUBA}

A inicios del siglo xx, Cuba sufrió profundas transformaciones ante la imposición de la Enmienda Platt y la celebración de las elecciones presidenciales que colocaron a Tomás Estrada Palma como primer presidente de la Isla. ${ }^{1}$ Estos acontecimientos políticos se desarrollaron en el contexto de la ocupación militar es-

1 Tomás Estrada Palma nació el 9 de julio de 1835, participó en la Guerra de los Diez Años (18681878) junto con Carlos Manuel de Céspedes; fue electo presidente de la República en Armas en marzo de 1876; fue capturado por las autoridades españolas y deportado a la Península ibérica, después de la firma del Pacto de Zanjón fue liberado; de Barcelona se trasladó a Honduras donde contrajo matrimonio. De ahí se dirigió a Nueva York y en Central Valley, condado de Orange, fundó una escuela para latinoamericanos. En este lugar, José Martí lo contactó para el establecimiento del Partido Revolucionario Cubano (PRC). Después de la muerte de Martí quedó al frente del PRC y del periódico Patria. En el movimiento "Cuba libre", Estrada Palma favorecía la participación de Estados Unidos en la Independencia de Cuba, de tal forma que de 1895 a 1898 se dedicó a cabildear con grupos de poder económico y político en la Unión Americana en pro de la independencia cubana. 
tadounidense y durante la administración del general Leonard Wood a finales de 1901 y principios de 1902. Lo que Estados Unidos buscaba era ligar el destino político de la Isla a los designios de Washington a través de la constitución de un gobierno afín a sus intereses, para después proceder a la evacuación del ejército que se encontraba en Cuba desde 1898.

Para los operadores políticos porfiristas, la posición de México era altamente relevante. El país, por su ubicación geográfica, formaba parte del escenario geopolítico donde Estados Unidos llevaba a la práctica su "primer experimento neocolonial" en la Perla de las Antillas. Cabe señalar que el gobierno de Porfirio Díaz reconoció de facto al gobierno interventor estadounidense en la Isla y tras la destitución de Andrés Clemente Vázquez se nombró, en 1902, a Gilberto Crespo Martínez representante diplomático en Cuba, cargo que ocuparía hasta $1905 .{ }^{2}$ México, al igual que sus contrapartes latinoamericanas, vislumbró el intervencionismo estadounidense en la Isla como una amenaza en ciernes para su seguridad nacional. En círculos oficiales, los operadores diplomáticos mexicanos mostraron una actitud neutral ante la conquista consumada en Cuba; algunos miembros del gabinete porfirista utilizaron a la prensa para expresar su recelo por el expansionismo estadounidense en el Caribe y Centroamérica. Los primeros comicios electorales del siglo xx cubano permitieron poner en la mesa del debate periodístico mexicano el carácter y la naturaleza de las relaciones cubano-estadounidenses.

A partir de la inclusión de la Enmienda Platt en la Constitución de Cuba, resultaba evidente que las riendas del poder en la Isla caribeña eran manejadas desde Washington, de ahí que el peso de la hegemonía estadounidense resultara abrumador y afectara el entramado continental. Situación ampliamente difundida en el ámbito de la opinión pública mexicana.

Los periódicos constituyeron los espacios de expresión político-ideológica en torno a los asuntos que ocurrían en la Gran Antilla. Es conveniente preguntarnos cómo se percibía en México a Estados Unidos, desde la perspectiva de la clase política mexicana, lo mismo que cuál sería la imagen de una Cuba que se vislumbraba

2 Margarita Espinosa, Diplomacia en entredicho [en prensa]. 
bajo el dominio de Washington. Estos cuestionamientos constituyen el eje vertebrador en la reconstrucción de la postura asumida por un segmento de la sociedad mexicana ante la problemática cubana. Por ello, las siguientes líneas se abocarán a la explicación de la actitud y postura del diario El Imparcial ante el intervencionismo estadounidense y las elecciones presidenciales. ${ }^{3}$

El análisis concienzudo de las relaciones cubano-estadounidenses y de las entabladas entre Cuba y México ha sido muy bien estudiado en los trabajos de Louis A. Pérez, Laura Muñoz, Margarita Espinosa y Salvador Morales, entre otros. Es conveniente señalar que la historiografía cubana y estadounidense ha privilegiado el estudio de la Enmienda Platt y su inclusión a la Constitución cubana. ${ }^{4}$ Así, la presente propuesta se perfila a valorar las opiniones vertidas en los editoriales y columnas de El Imparcial, con el afán de demostrar que las elecciones presidenciales y el establecimiento de la primera República en Cuba fue un elemento determinante en la generación de opiniones y actitudes en torno al intervencionismo estadounidense en el continente, y que abonó al debate ideológico que estaba teniendo lugar en suelo latinoamericano; el que vislumbraba al vecino del norte como una amenaza continental.

Dado el carácter más hemerográfico de este trabajo, conviene destacar algunos rasgos del periódico en cuestión. El Imparcial fue un diario capitalino, pro gobiernista, subvencionado por el régimen, fundado el 11 de septiembre de 1896 por Rafael Reyes Spíndola, quien fungió como su director, aunque en ocasiones fue sustituido por Carlos Díaz Dufóo. Este diario de gran formato era un difusor de las noticias del momento y de temas de interés general; su tiraje ascendía, para el periodo que nos ocupa, a 50 mil ejemplares. ${ }^{6}$ El periódico, a decir de la citada

3 Clara Guadalupe García, El periódico El Imparcial. Primer diario moderno de México (18961914), México, Centro de Estudios Históricos del Porfiriato, 2003.

${ }^{4}$ Leslie Buell, "Cuba y la Enmienda Platt", en Revista Bimestral Cubana, Sociedad Económica de Amigos del País, enero-febrero, 1934, p. 25; José A. Giralt, La supresión de la Enmienda Platt. Una serie de datos históricos acerca de la célebre Enmienda y una demostración plena de que puede y debe ser secundada, $2^{\mathrm{a}}$ ed., La Habana, 1933.

5 En 1900, Reyes Spíndola, en su viaje hacia la Exposición Internacional de París, hizo una escala en Cuba.

${ }^{6}$ Ibid., p. 139 
Clara Guadalupe García, era el "de mayor circulación y mejores posibilidades noticiosas en México" y pertenecía a la conocida prensa de a centavo. ${ }^{7}$

El autodenominado "Diario ilustrado de la mañana" contaba entre sus colaboradores con Ángel del Campo, Heriberto Frías, Juan de Dios Peza, Amado Nervo, Juan José Tablada, Carlos Díaz Dufóo, Luis G. Urbina y Manuel Flores; estos tres últimos se encargaban de escribir los editoriales. De igual manera, colaboraron Justo Sierra, Ezequiel Chávez y Alberto Correa. Este órgano periodístico, porfirista por convicción, se autoimpuso la tarea de "difundir el punto de vista político del gobierno desde una alta tribuna". ${ }^{8}$ De forma cotidiana publicaba cablegramas del New York Herald, provenientes directamente de Cuba, Washington, Londres y Nueva York y, a partir de 1898, de la Asociated Press y la Agencia Regagnon. ' La reproducción de notas provenientes de periódicos cubanos y estadounidenses permitió a los rotativos nacionales informar con prontitud de las relaciones Washington-La Habana. ${ }^{10}$

Hasta aquí nos queda claro el alcance nacional y la línea editorial de El Imparcial, caracterizada por su apoyo al gobierno de Díaz y la defensa del orden social existente, motivo por el cual al referirse a la "situación cubana", cuestiona a la política estadounidense y proporciona una bitácora del acontecer político de Cuba, uno de cuyos asuntos se refiere a la candidatura de Tomás Estrada Palma, que veremos a continuación.

El último trimestre de 1901 estuvo lleno de acontecimientos que conmovieron a la sociedad estadounidense y a la cubana. En la exposición de Búfalo, el presidente William McKinley fue asesinado por un anarquista y su lugar fue ocupado por el entonces vicepresidente, Theodore Roosevelt. Mientras tanto en

7 Ibid., p. 26.

8 Ibid., p. 57.

9 Ibid., p. 31. De acuerdo con la autora, El Imparcial, al menos hasta 1902, era el único órgano que recibía este servicio en México.

${ }^{10}$ Dentro del amplio espectro periodístico nacional se percibe la crítica al expansionismo estadounidense. El Universal no sólo era un periódico oficial sino claramente antinorteamericano. Para el liberal y abiertamente antihispanista El Diario del Hogar todavía se mantenía la creencia de que a pesar del estatus de dependencia de Cuba, la vida de los isleños era mejor con el nuevo régimen que con la dominación española. 
La Habana culminaban los trabajos de la Convención Constitucional y se aprobaba la Enmienda Platt como un apéndice de la Constitución. Simultáneamente, diferentes grupos políticos se aprestaban a postular la candidatura de Tomás Estrada Palma, que se convertiría en el primer presidente de la República de Cuba, decisión de implicaciones delicadas para la política exterior mexicana, a la luz del peso detentado por el gobierno militar norteamericano en la Isla. Por lo anterior, no resulta extraño que las elecciones presidenciales se convirtieran en uno de los principales asuntos de las relaciones cubano-estadounidenses abordadas en el rotativo de Reyes Spíndola.

En principio es conveniente destacar el pasado revolucionario de Estrada Palma y su linaje como sucesor de José Martí en el Partido Revolucionario Cubano (PRC), así como su afición a las costumbres y modelo político anglosajón, que le impidieron cuestionar la imposición de la Enmienda Platt en Cuba. Consideramos que esta afinidad y admiración hacia Estados Unidos constituyen el factor clave para ser apoyado por Elihu Root y Leonard Wood, secretario de Guerra y gobernador militar, respectivamente, y por sectores de propietarios pro anexionistas que postularon su candidatura a la presidencia de la República.

Efectivamente, en el mes de agosto de 1901, los partidos Republicano y Nacional le propusieron a Tomás Estrada Palma la candidatura a la presidencia de Cuba. También recibió el respaldo del generalísimo, Máximo Gómez. En contra parte, Bartolomé Massó fue postulado por los partidos Unión Democrática, el Nacionalista y el Republicano Independiente. De tal manera que los campos políticos se encontraban divididos entre los pro anexionistas, favorecedores de la Enmienda Platt y simpatizantes de Estrada Palma, y los antiplattistas y pro independentistas del lado de Massó. ${ }^{11}$

La plataforma electoral de Tomás Estrada y su programa de gobierno consideraban estrechar las relaciones con Estados Unidos, apoyando la puesta en práctica de la Enmienda Platt y en "cuidar que se interprete en todos los casos de manera más favorable a los intereses de Cuba, a su soberanía e independen-

${ }^{11}$ Jorge Ibarra, Cuba: 1898-1921. Partidos políticos y clases sociales, La Habana, Ciencias Sociales, 1992. 
cia" y la necesidad de signar un convenio de reciprocidad comercial con Washington "un tratado de reciprocidad comercial con los Estados Unidos en términos favorables a todos nuestros productos de exportación, principalmente el azúcar, cuya industria, que forma nuestra principal fuente de riqueza [ . . . y y el tabaco."12 Cabe señalar que Estrada Palma también apoyó los intereses estadounidenses sobre el arrendamiento de las estaciones navales en Guantánamo, Bahía Honda, y proponía resolver la indefinición territorial sobre la Isla de Pinos.

El candidato lanzó su plataforma electoral en Nueva York sugiriendo adoptar un programa de austeridad en las finanzas públicas, comprometiéndose a pagar la deuda contraída con el Ejército, previos ajustes y realización de un patrón exacto de los efectivos militares para evitar, en lo posible, afectar el erario público. ${ }^{13}$ Este programa de Estrada Palma, dado a conocer vía cable Nueva York-La Habana en carta a Rius Rivera el día 7 de septiembre de 1901, constituyó su base electoral, que no campaña, ya que Estrada Palma no realizó labor proselitista en la Isla. Su actuar en la contienda fue a la distancia, desde Estados Unidos. Estrada Palma confiaba su triunfo a la influencia de Wood y Root, y se encontraba seguro de obtener el apoyo y las simpatías de los oficiales militares del gobierno de ocupación en Cuba en torno a su candidatura; opinión compartida entre el sector azucarero y tabacalero ante la promesa de verse beneficiados con una posible reducción de los aranceles tarifarios a sus exportaciones.

A pesar de la fortaleza del "candidato" existían circunstancias amenazadoras para la obtención de la mayoría de los votos en las urnas. Un primer nubarrón fue la beligerancia de Massó, su opositor, quien convocó a sus seguidores a un mitin en el cual expuso con un lenguaje que no dejaba dudas su postura antiestadounidense y su compromiso en la defensa de una Cuba libre y soberana:

[... acepto como sacrificio del último combate que vamos a librar por nuestra sacrosanta aspiración a la independencia de la patria. No fuimos a la revolución para sucumbir, al final de ella, entre miserias humillados y rendidos como siervos, indiferentes a un mero cambio de dominación, ni pudo ser en ningún concepto,

${ }_{12}$ Hortensia Pichardo, Documentos para la Historia de Cuba, La Habana, Ciencias Sociales, 1969, t. II, p. 205.

${ }^{13}$ Loc. cit. 
María del Rosario Rodriguez Díaz

ideal de la contienda, la posesión de una parte del botín de guerra, siempre muy despreciable para poder extinguir o amenguar en la conciencia de los verdaderos aquel sublime anhelo, que fue en todo tiempo, doctrina de nuestros mentores, enseñanza de nuestros estadistas, divino ensueño de nuestros poetas [...]. La revolución hubo de ceder su puesto a la intervención que, falseada por una ocupación militar rayana en la conquista [...] concluyó por truncar la personalidad del país intervenido [...]. En estas circunstancias [.. . ] la república que va a fundarse no será en el orden universal un Estado independiente [... ]. Agradecidos eternamente al pueblo americano por su cooperación en esa empresa, y dispuestos a mantener con él en toda ocasión la cordialidad [...] se buscará la incorporación a cuadros del Partido Autonomista a las nuevas tareas de construcción de la república [... ] a la clase de color [... ] a los españoles [...]. El gobierno interventor perdió la oportunidad de reconstruir la "riqueza destrozada por la guerra" [...] fijadas en la adición constitucional, las relaciones con los Estados Unidos, huelga la repetición de mis propósitos de ser fiel intérprete y cumplidor de cuanto ha hecho la Convención Constituyente [ . . . resulte clara la firme decisión de no renunciar a nuestra nacionalidad soberana e independiente cuando su establecimiento sea posible. ${ }^{14}$

Naturalmente, el mitin de Massó y su manifiesto-programa en pro de la Independencia de Cuba inquietó a los estradistas, en particular el gobernador militar intensificó sus gestiones entre los gobernadores de las provincias a favor de Estrada Palma. De tal manera que el general Massó se sintió agredido por diferentes actores políicos, tanto en el ámbito doméstico como por la Unión Americana, por lo que se vio obligado a escribir una carta pública al presidente Roosevelt solicitándole contener al grupo de militares que hacían proselitismo en favor de Estrada Palma:

Hacemos a usted la súplica porque ciertos elementos militares tratan de asegurar a toda costa el triunfo de Estrada Palma, alegando la protección de Washington. El general Gómez en una carta abierta al pueblo cubano, aconseja que debe darse el voto a favor de Estrada Palma por razones que obedecen a una orden superior. Se comprende que la presión del ejército ocupante mucho tendrá que influir en el movimiento electoral, aunque el mismo Roosevelt se empeñe en destruirla. ${ }^{15}$

${ }^{14}$ El Diario del Hogar, México, 19 de noviembre, 1901.

${ }^{15}$ El Diario del Hogar, México, 2 de diciembre, 1901. 
La respuesta a Massó provinó del secretario Elihu Root, quien en nombre de Roosevelt refrendó al candidato Massó el respeto a los comicios presidenciales al señalarle: "los oficiales de ocupación no tomarán injerencia alguna". ${ }^{16}$

¿Cuál fue la postura de El Imparcial en medio de este ambiente de tensiones y confrontaciones políicas? En principio el periódico destaca el pronunciamiento del general Máximo Gómez en favor de la candidatura de Tomás Estrada Palma, apoyado por los partidos Republicano y Nacional y por el Círculo de Hacendados de La Habana. También incluyó la postulación del Partido Unión Democrática, el Nacionalista y el Republicano Independiente a favor de Bartolomé Massó. ${ }^{17}$

El discurso de este diario oficialista se caracterizó por adoptar una línea editorial de crítica al expansionismo estadounidense, y cumplió una eficaz labor de difusor de las advertencias gubernamentales ante el peligro que representaba para la seguridad nacional la consolidación de la influencia estadounidense sobre el destino de Cuba. Es conveniente tener en cuenta que órganos periodísticos conservadores, católicos y filo hispanistas, durante la coyuntura del '98 centraban "su atención en la crítica furiosa a los Estados Unidos, a sus prácticas y políticas [...]."18 Por ello, se habla de una identificación de esta prensa conservadora, salvo matices discursivos, con el tono crítico a la Unión Americana, expresado en periódicos de corte liberal y oficialista como el órgano de referencia del presente trabajo. Consideramos que tales puntos de convergencia discursiva son indicativos de los vientos antiestadounidenses que corrían por América Latina y el Caribe y del rampante nacionalismo latinoamericano de principios del siglo $\mathrm{xx},{ }^{19}$ como se comprobará en las muestras periodísticas seleccionadas.

Entre los meses de septiembre de 1901 a julio del siguiente año, El Imparcial dio a conocer más de 75 notas entre cables y editoriales. El amplio espacio

${ }^{16}$ El Universal, México, 4 de diciembre, 1901.

17 Bartolomé Massó había sido compañero de Carlos Manuel de Céspedes en el levantamiento de 1868, último presidente de la República en Armas en 1895. Aglutinó a los opositores de la Enmienda Platt.

${ }^{18}$ Salvador Morales, "Cuba y Estados Unidos vistos por la prensa conservadora", en Revista Mexicana del Caribe, núm. 5, Universidad de Quintana Roo, 1998, p. 161.

19 El discurso periodístico mexicano abona a los debates ideológicos entre los "ismos" el hispanoamericanismo versus el panamericanismo que está teniendo lugar en el continente. 
que se dedica a temas cubanos coincide con los momentos coyunturales -entre mediados de octubre de 1901 y enero-febrero de 1902-, del desarrollo de la predecible campaña electoral, aunque también se puede apreciar, dentro de este periódico, una amplia cobertura de los acontecimientos regionales y continentales, ponderando la figura de Díaz como líder latinoamericano y el papel de México como ejemplo a seguir por su estabilidad política y crecimiento económico.

Un examen de los artículos y cablegramas publicados a partir de la imposición de la Enmienda Platt, ${ }^{20}$ en el segundo semestre de 1901 y principios de 1902, arroja como resultado la importancia que revestían los sucesos que tenían lugar en suelo cubano para México. De los materiales publicados en el periódico El Imparcial destacaron por su relevancia las notas y cablegramas que daban cuenta de la polarización políica existente entre los partidarios de la anexión y los independentistas, representados en la contienda presidencial por Tomás Estrada Palma y Bartolomé Massó, respectivamente. El Imparcial presentaba el pulso político electoral de la Isla y basado en el respaldo de Washington y de la Asociación de Manufactureros de La Habana a la candidatura de Tomás Estrada Palma, vaticinaba el triunfo de éste y pronosticaba que el general Massó aceptaría en el último momento su candidatura para vicepresidente. Nada más alejado de la realidad; Massó no sólo rechazó tal propuesta, sino que se retiró de la contienda no sin antes denunciar que se trataba de un proceso electoral artificial y a modo de los estadounidenses.

El Imparcial publicó de manera regular dos secciones: La liberación de Cuba y la Independencia de Cuba que contenían su opinión acerca del proceso político cubano; cabe destacar que dichos encabezados contrastaban con los

${ }^{20}$ Cuba no podía realizar pactos internacionales ni contraer deudas con otros países sin el consentimiento de Estados Unidos, país que tendría el derecho de intervenir militarmente en la Isla si se subvertía el orden o se lesionaban los intereses y la vida de los ciudadanos norteamericanos, por lo que se autorizó el establecimiento de bases navales. Sin alternativa posible para lograr una independencia plena, poco a poco se fue despejando la ola de oposición a la Enmienda Platt. El 4 de abril Manuel Sanguily, uno de sus más férreos críticos, la aprobó, no sin antes señalar que una "independencia con restricciones es mejor que alargar la ocupación". Esta actitud la siguieron las diferentes organizaciones y líderes políticos. A Gonzalo de Quesada le correspondió informar a Wood que la Enmienda había sido aprobada el 12 de junio, con 16 votos a favor y 11 en contra. 
contenidos que alertaban sobre los peligros que se cernían para el non nato sistema representativo políico cubano; se comentaba sobre el fenómeno del abstencionismo culpándose a los operadores políticos estadounidenses de organizar unas elecciones arregladas. Ejemplo de ello es la siguiente nota periodística:

Llama la atención el pequeño número de votos que se recogerán porque la mayoría de los cubanos se han abstenido de votar porque se cree que la victoria es segura. También se realizó una protesta del pueblo contra la imposición de candidatos oficiales, y se asegura que la política americana acabará por matar la democracia en Cuba. ${ }^{21}$

El Imparcial, al enfatizar las limitaciones del proceso electoral cubano y el carácter de Estrada Palma como el candidato de la Casa Blanca, contribuía a subrayar el estatus de Cuba como nación intervenida y bajo el protectorado estadounidense, y por ello daba por hecho la victoria de Palma. Además el extendido abstencionismo de los partidarios de Massó, como una muestra de inconformidad ante la imposición de la candidatura de la Casa Blanca en la figura de Palma, le allanó el camino al oriundo de Bayamo para ocupar la primera magistratura de Cuba. Efectivamente, Estrada Palma resultó triunfador en la primera contienda electoral cubana del siglo xx.

Los resultados electorales muestran el contundente triunfo de Estrada Palma, El Imparcial incluía aseveraciones sobre las tareas que encabezaba el presidente electo y señalaba a la Unión Americana todavía como su lugar de residencia:

El presidente Estrada Palma obtuvo 55 electores mientras que su contrincante sólo 8 [...]. El señor Estrada Palma aún se encuentra en su residencia en New York. El presidente cubano declaró que sus deseos son asegurar y fortalecer las relaciones entre Cuba y Estados Unidos y en segundo lugar favorecer el desarrollo económico de su país, principalmente el ramo de la agricultura. Ha prometido tratar de conseguir la reducción de las tarifas americanas referentes a productos

${ }^{21}$ El Imparcial, 23 de febrero. "Presidente de la República Cubana". El señor Estrada Palma va a ser formalmente nombrado mañana, presidente de la República de Cuba. 
de la isla, y dijo que en su labor en la presidencia sería igual a la de cualquier artesano o labrador del campo. ${ }^{22}$

Las felicitaciones por el triunfo de Estrada Palma no se hicieron esperar. El virtual presidente recibió con beneplácito las muestras de apoyo, aunque lamentó que el general Massó no hubiera querido aceptar la vicepresidencia. ${ }^{23}$

Al mismo tiempo que se publicaban las felicitaciones dirigidas a Tomás Estrada Palma por los delegados de la Segunda Conferencia Panamericana reunidos en la ciudad de México, se realizó la inserción de una nota que revelaba la propuesta en el seno del Congreso estadounidense de anexar Cuba a Estados Unidos, develando que el impulso anexionista se negaba a morir:

El representante de Newlands presentó a la cámara un proyecto de ley para que se le invite a Cuba a que se anexe a los Estados Unidos, primero como un territorio y después como un estado de la Unión Americana. En la misma proposición pide que se reduzcan los derechos del tabaco y del azúcar, que se importan de la isla, en un $25 \%{ }^{24}$

En sus páginas El Imparcial cumplía con su labor de informante del desarrollo de los acontecimientos nacionales y regionales. La mayor parte de sus informes eran noticias que reflejaban la postura de los principales actores políticos cubanos y estadounidenses. Algunas veces figuraron en primera plana y de manera extensa asuntos cubanos de trascendencia regional, como el tratado de reciprocidad Cuba-Estados Unidos que proyectaba la reducción de impuestos a las exportaciones azucareras y tabacaleras cubanas a Estados Unidos; así como se publicaba su contenido, las opiniones entre los congresistas en Washington y en La Habana y las negociaciones que se estaban realizando. ${ }^{25}$ Cabe señalar que en el tratamiento de este asunto se incluían las posibles implicaciones para el ramo azucarero mexicano, y algunas propuestas del editorialista sobre la necesidad

${ }^{22}$ El Imparcial, 4 de enero, 1902.

${ }^{23}$ El Imparcial, 2 de enero, 1902.

${ }^{24}$ El Imparcial, "Anexión de Cuba", 7 de febrero, 1902.

${ }^{25}$ La firma de un tratado de reciprocidad era vital para la asociación de manufactureros y exportadores cubanos, quienes impulsaban un proyecto anexionista. 
de México de diversificar sus relaciones y buscar mercados alternos en Centroamérica y en Europa para reducir su dependencia del vecino del norte. Cuestiones que abordaremos en el siguiente apartado.

\section{El Tratado de Reciprocidad Cuba-Estados Unidos}

En virtud de la polarización política existente entre los partidarios de la anexión y los autonomistas, representados en la contienda presidencial por Estrada Palma y Massó, respectivamente, y ante el peligro de que se formara una fuerza política suficiente para desafiar a Estados Unidos, el secretario de Guerra de este país, Elihu Root, urgía al Congreso a la aprobación de un tratado comercial que consignara una reducción de impuestos a las importaciones y exportaciones cubanas, y detonara el desarrollo económico cubano. ${ }^{26}$ Es decir, los intereses político-estratégicos iban de la mano con los económico-comerciales.

Existía una coincidencia entre los grupos económicos dominantes cubanos y el gobierno de Roosevelt, recientemente ascendido como consecuencia del asesinato de William McKinley a principios de septiembre. Roosevelt, como vicepresidente en la anterior administración, favoreció las políticas de Root en Cuba y le dio continuidad y apoyo a sus planteamientos de lograr una reducción a las exportaciones cubanas. En esta línea, después de muchos avatares y cabildeos, el tratado fue incluido en la agenda del Congreso. El Imparcial reseñó la noticia en los siguientes términos:

En la sesión de ayer del senado, se presentó una proposición en la que se autoriza al gobierno para que cuando se establezca el gobierno autóctono en Cuba, se emprendan negociaciones con él, encaminadas a conseguir un tratado de reciprocidad con la nueva república. En el proyecto de ley se expresa que si se consigue dicho tratado de reciprocidad, el gobierno americano queda autorizado para disminuir hasta en un $80 \%$, los derechos aduanales que pagan hoy los artículos cubanos. ${ }^{27}$

${ }^{26}$ W. L. Bass, a Cuban Relief Measure. As Opposed to an Absence of Any Relief to the Cubans in the Inmediate Future and a Percentage Reduction of Federal Customs or Other Pro-monopoly Measures, Washington, 2 de febrero, 1902.

${ }^{27}$ El Imparcial, "La reciprocidad con Cuba", 20 de marzo, 1902. 
Maria del Rosario Rodriguez Diaz

De esta manera, la agenda cubano-estadounidense en materia económica recibía cobertura noticiosa, no menos importante era la difusión de los pasos tendientes a la "Liberación de Cuba", tal y como reza el encabezado de El Imparcial de la siguiente nota periodística:

El general Wood, gobernador de Cuba, ha dicho que la proyectada reducción de 20\% en los derechos de Cuba, no es suficiente. El general permanecerá algún tiempo después del cambio de gobierno en la isla y que una pequeña cantidad de tropas permanecerá también. Parece que es el deseo de los cubanos. Una reducción menor de 20\% sobre el azúcar de la isla será motivo de una crisis en la industria azucarera. La mayoría de los productos cubanos son consumidos en los Estados Unidos, y no hay motivo para temer que el gobierno no preste este auxilio a Cuba, rebajando los derechos actuales, que son demasiado altos. Una reducción del 30\% sería muy razonable y prestaría utilidad efectiva a la industria cubana azucarera. El general Wood juzga que los Estados Unidos son responsables de la prosperidad de Cuba y que una reducción como la que indica de 33\%, no sería motivo de disturbio para las finanzas americanas. ${ }^{28}$

El impulso de Wood al logro de una reducción de impuestos a las exportaciones cubanas iba a tono con los esfuerzos y exigencias del secretario Elihu Root en el Capitolio. Aun más, por la siguiente nota nos podemos percatar que desde la Casa Blanca se negociaba con los grupos del partido Republicano, contrarios a la firma de un tratado de reciprocidad con Cuba:

El presidente Roosevelt celebró una junta con representantes republicanos que se han opuesto a la reciprocidad con Cuba. La reunión tuvo por objeto armonizar la acción de los republicanos en el Congreso, tomando en cuenta los diversos intereses que están en juego en la cuestión de la reciprocidad. Por su parte el presidente se encuentra en disposición de conceder a Cuba la reciprocidad, en vista de que sería poco equitativo limitar ésta al $1^{\circ}$ de diciembre de 1903 , en tanto que se pide a Cuba acepte las leyes americanas de emigración y de naturalización por un periodo de tiempo indefinido.

${ }^{28}$ El Imparcial, "La liberación de Cuba", 24 de marzo, 1902. 
Los representantes estuvieron conformes en que los Estados Unidos han pedido demasiado a Cuba, sin concederle en cambio lo que sería justo. A pesar del cambio de opiniones no se llegó a ningún acuerdo y se seguirá sesionando sobre este asunto. ${ }^{29}$

Simultáneamente, se daba cuenta de los trabajos del congreso sanitario internacional en La Habana y del banquete ofrecido en honor de los delegados. ${ }^{30}$

Las felicitaciones de miembros de la colonia cubana en México fueron publicadas prontamente, éstos, en principio, encomiaron la iniciativa de elevar al rango de Legación a la representación diplomática en Cuba: los señores Pedro Santacilia, Rafael Arozamena y Nicolás Domínguez visitaron al ministro Mariscal, a nombre de la colonia cubana en México. El señor Santacilia tomó la palabra para decir que a nombre de la colonia cubana y de Cuba misma querían expresar a México, por conducto de su ministro de Relaciones, su profundo agradecimiento por haberse apresurado a reconocer a la República de Cuba, y acreditar en ella una Legación.

El primer presidente de la República de Cuba se mantenía ocupado desde su residencia en Nueva York contestando los cablegramas de felicitación ante su victoria electoral tan cómoda. Los diferentes niveles de gobierno en Washington también dedicaban gran parte de su tiempo en la organización de la transferencia del poder a los cubanos. De entrada El Imparcial informó, lacónicamente, el establecimiento de la fecha de entrega del gobierno:

[... se se anunció que el gobernador militar y el secretario Elihu Root acordaron que la entrega del gobierno se realizaría el 20 de mayo de 1902 al mediodía. ${ }^{31}$ Y que [... éste será el principio de la retirada de las fuerzas americanas, para que sea establecido el gobierno civil en la isla. ${ }^{32}$

${ }^{29}$ El Imparcial, "La reciprocidad en Cuba", 26 de marzo, 1902.

${ }^{30}$ El Imparcial, "El Congreso de La Habana", 2 de marzo, 1902

${ }^{31}$ Orden Civil, núm. 158, Wood Papers.

32 El Imparcial, 7 de enero, 1902. 
Maria del Rosario Rodriguez Diaz

La coordinación para el cambio de poderes realizado desde Estados Unidos era de relevancia tal que no podía llevarse a cabo a través de los cablegramas, sino que obligó a funcionarios cubanos a trasladarse a suelo neoyorkino para arreglar lo relacionado a la transferencia del poder. El rotativo mexicano señalaba lo siguiente:

El señor Méndez Capote, acompañado del secretario de Estado Sr. Tamayo, zarpó para New York con objeto de consultar con el Sr. Estrada Palma, presidente electo de Cuba, los detalles relativos a la toma de posesión de éste, que se aproxima ya. ${ }^{33}$

A su vez El Imparcial reseñaba las pláticas entre Wood y Palma:

El general Wood se encuentra discutiendo con el presidente Estrada Palma todo lo relativo a la entrega total de los poderes públicos de Cuba a los funcionarios electos. Se busca que la entrega se haga de la manera más pronta posible. El general Wood conferenciará con el presidente Estrada Palma, que debe empezar la administración el $1^{\circ}$ de mayo. ${ }^{34}$ La cuestión de la entrega total del gobierno de Cuba ha sido tratada en una conferencia del general Wood con el presidente Estrada Palma. La entrega del gobierno se cree que no dará lugar a dificultades de ningún tipo. ${ }^{35}$

En otra edición señalaba la entrevista entre el presidente Roosevelt, Estrada Palma y funcionarios cubanos, anunciando la salida de Estrada Palma a Cuba. ${ }^{36}$

Se celebró una importante conferencia en la Casa Blanca entre el presidente Roosevelt, y el presidente Estrada Palma, respecto al porvenir de Cuba, con la asistencia del señor Root, Wood, Gonzalo de Quesada, entre otros. En esta conferencia se determinó que la evacuación de Cuba por las tropas americanas se aplazará hasta el mes de Mayo, es decir, hasta el día en que Palma empiece a

${ }^{33}$ El Imparcial, "El nuevo gobierno de Cuba", 17 de marzo, 1902.

${ }^{34}$ El Imparcial, "El gobierno de Cuba", 23 de marzo, 1902.

35 El Imparcial, "El gobierno de Cuba", 25 de marzo, 1902.

${ }^{36}$ El Imparcial, "La liberación de Cuba", 26 de marzo, 1902. El general Estrada Palma visitó al presidente Roosevelt, en unión de varios cubanos distinguidos. La reunión fue de carácter netamente social, pero se trataron en ella diversos asuntos referentes a la entrega que haría próximamente el gobierno americano de la isla de Cuba a los funcionarios electos por el voto 
desempeñar las altas funciones de presidente. Se resolvió también que sólo una pequeña parte de las fuerzas quedaría estacionada cerca de los parajes en la costa de Cuba. El presidente habrá de enviar un mensaje especial al Congreso en el que manifieste su intención de hacer evacuar de la isla los soldados americanos. ${ }^{37}$

En el Congreso estadounidense fueron aprobados los siguientes artículos respecto a Cuba: la resolución citada previene que Cuba no podrá arreglar tratados referentes a su soberanía con potencias extranjeras sin que intervenga el gobierno americano. El gobierno cubano no podrá conseguir empréstitos que no sean necesarios en el momento para las atenciones de la Isla. El gobierno de Estados Unidos tiene derecho a intervenir siempre que se trate de la libertad de Cuba y del cumplimiento de las obligaciones de dicho gobierno. ${ }^{38}$

En Washington, el Comité de Medios y Arbitrios del Congreso decidió dictaminar que se concedía la disminución de 20\% de los derechos de exportación de artículos cubanos. Además se hizo una ligera enmienda para que el gobierno de Estados Unidos pusiera en vigor tanto el decreto relativo a los jornaleros como la ley de inmigración. ${ }^{39}$ Para El Imparcial quedaba claro que la cuestión de la reciprocidad con Cuba y la adopción de las leyes de inmigración habían generado debates y tensiones entre los congresistas de filiación demócrata y republicana. ${ }^{40}$ Efectivamente, fue muy pequeño el margen de votos que puso fin al asunto más relevante de la agenda cubano-estadounidense: la reducción tarifaria. De ello da cuenta el siguiente cablegrama:

En la Cámara estadounidense se llevó a cabo la votación para dar principio a la discusión del asunto de la reciprocidad con Cuba. 113 republicanos y 63 demócratas votaron afirmativamente y 41 demócratas y 39 republicanos por la negativa. ${ }^{41}$

\footnotetext{
popular. Se fijó la fecha del $1^{\circ}$ de mayo para la ceremonia de entrega oficial. El presidente Estrada Palma saldría de Washington para estar en los días inmediatos a abril en Cuba.

${ }^{37}$ El Imparcial, "El porvenir de Cuba", 27 de marzo, 1902.

38 El Imparcial, "La misión diplomática en Cuba", 28 de marzo, 1902.

39 El Imparcial, "El tratado cubano-americano", $1^{\circ}$ de abril, 1902.

${ }^{40}$ El Imparcial, "La reciprocidad cubana", 7 de abril, 1902.

${ }^{41}$ El Imparcial, "Asunto de reciprocidad", 9 de abril, 1902.
} 
Maria del Rosario Rodriguez Díaz

No obstante la votación que aprobaba el Tratado de Reciprocidad con Cuba, en el recinto legislativo se siguieron discutiendo sus posibles implicaciones para las compañías azucareras estadounidenses. ${ }^{42} \mathrm{Al}$ tiempo que esto acontecía, el secretario de Guerra, Elihu Root y el presidente electo se embarcaron simultáneamente de la Unión Americana a Cuba, cada uno con una agenda muy definida y con un objetivo común: transferir el gobierno a los cubanos. En la siguiente nota se señala:

El presidente Estrada Palma se ha embarcado rumbo a su ciudad natal.

En otras noticias, el señor Elihu Root, secretario de Guerra, se ha embarcado para La Habana, al respecto dijo, "voy simplemente a ver lo que pasa en Cuba, en lo que concierne a mi ramo y a formular más planes para que las tropas desocupen la isla el día 30 de mayo". 43

La Reciprocidad Cubana y el Tratado Cubano Americano fueron los encabezados en los cuales El Imparcial reproducía de manera extensa lo tocante a las relaciones económico-comerciales entre Estados Unidos y Cuba.

La votación sobre la ley de reciprocidad cubana dio principio hoy en la cámara de diputados. Se votó primero una enmienda presentada por la presidencia de la comisión, para que fuera quitado el derecho adicional que tienen los azúcares refinados, durante el tiempo que dure la reciprocidad. La votación dio 171 en pro y 130 en contra, y en seguida fue aprobada la medida que había propuesto la presidencia. La junta que tuvieron la noche pasada los jefes del partido republicano sirvió para que se uniformara la opinión que estaba divida. La ley autoriza al presidente para arreglar con el gobierno cubano, relaciones de comercio sobre la base de la reciprocidad en los beneficios. Los Estados Unidos harán una reducción del 20\% sobre las contribuciones que marca la tarifa Dingley, hasta el día $1^{\circ}$ de diciembre de 1903. Durante la existencia de esta disposición, la tarifa sobre el azúcar refinado es de 1.825 , por libra de artículo. ${ }^{44}$

${ }^{42}$ El Imparcial, "La ley de reciprocidad con Cuba", 10 de abril, 1902.

${ }^{43}$ El Imparcial, "El viaje del presidente Estrada Palma", 18 de abril, 1902.

${ }^{44}$ El Imparcial, "La reciprocidad cubana", 19 de abril, 1902. 
Una vez pasadas las elecciones, a partir del mes de abril de 1902, El Imparcial se enfocó en reseñar el itinerario de Tomás Estrada Palma desde su salida de Nueva York, su llegada a Cuba y su recorrido por las provincias de Holguín, Bayamo, Santiago, Santa Cruz y Cienfuegos - donde fue objeto de agasajos y homenajes-, y se incluyó la felicitación del ex candidato Bartolomé Massó. ${ }^{45}$ Por el mencionado diario capitalino sabemos que el 10 de mayo se encontraba en Matanzas. ${ }^{46}$

Como se señaló líneas arriba, el periplo de Estrada Palma coincidió con el viaje de Elihu Root. El secretario de Guerra dijo que el objetivo de su visita a Cuba fue para arreglar todo lo concerniente al traspaso del gobierno de la Isla a las autoridades electas. Señaló que alrededor de 800 miembros del ejército estadounidense se quedarían en Cuba mientras se arreglaba la formación del Ejército cubano. ${ }^{47}$

La edición del 14 de mayo destaca el establecimiento de una Legación mexicana en Cuba:

La inauguración en la isla de Cuba de un gobierno autónomo ha determinado al gobierno mexicano a reconocer el nuevo régimen, y por consiguiente a establecer en aquella isla una Legación. Habrá que modificar la planta del consulado en La Habana, tener allí un cónsul general y un canciller, además de un cónsul particular y un escribiente. ${ }^{48}$

En el seguimiento periodístico realizado, llama la atención el tono de crítica hacia la actuación de Estados Unidos en la Isla y es que el 22 de mayo de 1902 se firmó por los delegados plenipotenciarios de Cuba y Estados Unidos un Tratado Permanente en el que se incluían los siete primeros artículos del apéndice constitucional: "Por la misma razón de que los Estados Unidos han ayudado a Cuba a ser libre, deben ayudarla a progresar, siquiera porque no se diga que se aprovecharon de sus condiciones de debilidad incipiente para medrar a costa de ella." ${ }^{39}$

${ }^{45}$ El Imparcial, 22 de abril, 1902.

${ }^{46}$ Loc. cit.

${ }^{47}$ El Imparcial, 28 de abril, 1902.

${ }^{48}$ El Imparcial, 17 de mayo, 1902.

49 El Imparcial, 14 de junio, 1902. 
En esta misma fecha, El Imparcial destacó el comunicado del secretario de Relaciones Exteriores, Ignacio Mariscal, quien por instrucciones del presidente Porfirio Díaz mandó a Estrada Palma y al pueblo cubano un cablegrama de felicitación augurando éxito y felicidad al pueblo cubano. En respuesta, Estrada Palma agradeció los buenos deseos de sus contrapartes mexicanos entusiastamente:

Señor presidente de la Cámara de Diputados de México.

Mucho agradezco su saludo y los votos que hace por el porvenir de Cuba, nacida hoy a la vida nacional, confío en que a la sombra de las instituciones democráticas que nos han de regir, Cuba alcanzará la estabilidad que ustedes le desean.

Tomás Estrada Palma. ${ }^{50}$

\section{CONCLUSIONES}

Queda mostrado así que las relaciones cubano-estadounidenses estuvieron presentes en la prensa mexicana de la época. El periódico seleccionado, al abordar el acontecer político cubano, utilizó un discurso que reflejaba la ambivalencia de la políica exterior del gobierno porfirista hacia su vecino del norte. Este diario adoptó una línea editorial de crítica al gobierno estadounidense haciendo eco a las manifestaciones de los círculos gubernamentales, en cuanto al riesgo latente para la seguridad nacional mexicana que representaba el expansionismo norteamericano en el Caribe y Centroamérica. El discurso periodístico de El Imparcial se manifestó apegado a los círculos oficiales, por lo que adoptó una posición ambigua, pues por un lado alababa a Estados Unidos por dar por terminado el gobierno de ocupación en la Isla, y por otro denunciaba la intromisión estadounidense en los comicios cubanos. Las muestras periodísticas examinadas nos permiten inferir que la postura de El Imparcial al defender el derecho de Cuba a la libertad e independencia difundía el discurso político del gobierno

${ }^{50}$ El Imparcial, 22 de mayo, 1902. 
mexicano, tendiente a la defensa de la soberanía nacional y a expresar veladamente su oposición a la prolongación de la influencia estadounidense en Cuba.

Referente al ascenso de Estrada Palma a la presidencia de la República de Cuba, podemos señalar que no significó una ruptura con el actuar estadounidense hacia la Isla, sino la culminación de un proceso jurídico-político que condicionó la existencia de Cuba como nación dependiente y bajo el protectorado de Estados Unidos durante más de medio siglo.

Recibido: 6 de septiembre, 2011 Aceptado: 26 de septiembre, 2011.

FUENTES

HeMEROGRAFíA

El Imparcial, México, 1901-1902.

\section{DOCUMENTOS}

Rules and Instructions to carry into effect the executive orders relating to the military government of the United States in the Island of Cuba and All Islands in the West Indies West of the Seventy-Fourth Degree, West Longitude, Evacuated by Spain, during the Maintenance of Such Military Government, War Department, Washington, 1899-1902.

The Establishment of free Government in Cuba, Bureau of Insular Affairs, War Department, Government Printing Office Washington, 1904.

US Congress Senate Committee on Relations with Cuba, Statement of Leonard

Wood, Government Printing Office, Washington, 1902. 
María del Rosario Rodríguez Díaz

\section{BIBLIOGRAFÍA}

BAss, W. L., A Cuban Relief Measure. As opposed to an absence of any relief to the Cubans in the inmediate future and a percentage reduction of federal customs or other Pro-monopoly measures, Washington, 2 de febrero, 1902.

Carreras, Julio A., Historia del Estado y el Derecho en Cuba, La Habana, Ministerio de Educación Superior, 1981.

Chapman, Charles E., A History of The Cuban Republic. A Study in Hispanic American Politics, Nueva York, Octagon Books, 1969, p. 154.

FitzGiBon, Russell H., Cuba and the United States, 1900-1935, New Cork, Russell \& Russell, 1964.

Frankun, Jane, Cuba and the United States. A chronological History, Nueva York, Ocean Press, 1997.

IBARRA, Jorge, Cuba: 1898-1921. Partidos políticos y clases sociales, La Habana, Ciencias Sociales, 1992.

PÉREZ, Louis A., "Insurrection, Intervention, and the Transformation of Land Tenure Systems in Cuba, 1895-1902", en Hispanic American Historical Review, vol. 2, núm. 65, Duke University Press, 1985, p. 234.

Wilson, James H., Our Relations With Cuba. At the Request of the Commercial Club of Chicago, 25 de octubre, 1902, The John M. Rogers Press, Wilmington, Del., 1902. 